\title{
ON THE DISINTEGRATION OF ICE SHELVES: THE ROLE OF THINNING
}

\author{
by \\ T. J. Hughes \\ (Department of Geological Sciences and Institute for Quaternary Studies, University of \\ Maine at Orono, Orono, Maine 04469, U.S.A.)
}

\section{ABSTRACT}

It is proposed that an ice shelf disintegrates when its calving front retreats faster than its grounding line. This paper examines the role of ice thinning in grounding-line retreat. Thinning occurs as a result of creep spreading and ice melting. Thinning by creep is examined for the general regime of bending converging flow in an ice shelf lying in a confined embayment, and at the grounding lines of ice streams that supply the ice shelf and ice rises where the ice shelf is grounded on bedrock. Thinning by melting is examined at these grounding lines for tidal pumping and for descent of surface melt water into strandline crevasses, where concentrated melting is focused at the supposed weak links that connect the ice shelf to its embayment, its ice streams, and its ice rises. Applications are made to the Ross Ice Shelf.

\section{INTRODUCTION}

Antarctic ice shelves typically lie in confined embayments. Suppose that, within its embayment, an ice shelf is held together by weak links to the ice streams that supply it and to the ice rises where it is anchored to bedrock. Then the ice shelf might fragment if these weak links were all broken. This is an assumption. However, shear rupture alongside the floating tongue of Byrd Glacier (Hughes 1979) and shear/fatigue rupture around Crary Ice Rise (Barrett 1975) have locally fractured the entire thickness of the Ross Ice Shelf. This tendency to disintegrate, if it is real, can be counteracted if retreating grounding lines create new ice-shelf ice as fast as the old ice shelf disintegrates.

An ice shelf is carved away by a calving bay if $i$ ts calving front retreats faster than $i$ ts grounding line. Fastook and Schmidt (1982) have examined calving rates, including those expected when climatic warming places the ice shelf in an ablation zone. This paper examines the role of ice thinning on grounding-line retreat rates caused by both creep and melting, with applications to the Ross Ice Shelf.

\section{THINNING BY CREEP}

Two assumptions govern the relationship between the stress tensor $\sigma_{i j}$ and the strain-rate tensor $\dot{\varepsilon}_{i j}$ (tensor subscripts $i, j, k$ refer to the rectilinear axes $x, y, z$ in succession, according to standard tensor notation). First, a given strain-rate component is proportional to the corresponding deviator stress component $\sigma_{i j}^{\prime}$, where $\sigma_{i j}=\sigma_{i j}-1 / 3 \delta_{i j} \sigma_{k k}, \delta_{i j}$ is the Kronecker delta, and okk is the first invariant of stress. Second, the proportionality constant is assumed to be a function only of the second invariant of deviator stress $\tau^{2}$, where $\tau=\left(1 / 2 \sigma_{j} \sigma_{i j}\right)^{1 / 2}$. The precise functional relationship in the empirical flow law of ice requires that ice be incompressible, $\dot{\varepsilon}_{\text {kk }}=0$, and is (G1en 1958):

$$
\dot{\varepsilon}_{i j}=\left(\tau^{n-1} / A^{n}\right) \sigma_{i j}^{i},
$$

where $A$ is a hardness coefficient and $n$ is a viscoplastic exponent.

Consider a horizontal ice shelf with $x$ directed along a surface flow line, $y$ transverse to the flow line, and $z$ vertically upward. Principal surface strain-rates $\dot{\varepsilon}_{1}$ and $\dot{\varepsilon}_{2}$ are frequently different from strain-rates $\dot{\varepsilon}_{x x}$ and $\dot{\varepsilon}_{y y}$, but $\dot{\varepsilon}_{3}=\dot{\varepsilon}_{z z}$ everywhere. In terms of principal stresses, the first assumption permits a ratio $R$ such that:

$$
R=\frac{\dot{\varepsilon}_{2}}{\dot{\varepsilon}_{1}}=\frac{\sigma_{2}^{\prime}}{\sigma_{1}^{\prime}}=\frac{\sigma_{2}-1 / 3\left(\sigma_{1}+\sigma_{2}+\sigma_{3}\right)}{\sigma_{1}-1 / 3\left(\sigma_{1}+\sigma_{2}+\sigma_{3}\right)}
$$

where subscripts $1,2,3$ denote principal components of stress and strain-rate. Solving Equation (2) for $\sigma_{2}$ gives:

$$
\sigma_{2}=\left(\frac{2 R+1}{2+R}\right) \sigma_{1}+\left(\frac{1-R}{2+R}\right) \sigma_{3} .
$$

Substituting Equation (3) into the expression for in terms of principal stresses gives:

$$
\begin{aligned}
\tau & =\left(\frac{1}{6}\left[\left(\sigma_{1}-\sigma_{2}\right)^{2}+\left(\sigma_{2}-\sigma_{3}\right)^{2}+\left(\sigma_{3}-\sigma_{1}\right)^{2}\right]\right)^{\frac{1}{2}} \\
& =\left(1+R+R^{2}\right)^{\frac{1}{2}} \frac{\sigma_{1}-\sigma_{3}}{2+R} .
\end{aligned}
$$

Substituting Equation (3) into the expression for $\sigma_{1}^{\prime}$ in terms of principal stresses gives: 
$\sigma_{1}^{\prime}=\sigma_{1}-\frac{1}{3}\left(\sigma_{1}+\sigma_{2}+\sigma_{3}\right)=\frac{\sigma_{1}-\sigma_{3}}{2+R}$.

Substituting Equations (4) and (5) into Equation (1) gives the flow law for a horizontal ice shelf in terms of $R$ and its principal stresses $\sigma_{1}$ and $\sigma_{3}$ :

$$
\dot{\varepsilon}_{1}=\left(1+R+R^{2}\right)^{(n-1) / 2}\left[\frac{\sigma_{1}-\sigma_{3}}{(2+R) A}\right]^{n} .
$$

Terms containing $R$ in Equation (6) can be collected to form a constant $R^{\prime}$ defined as:

$$
R^{\prime}=\frac{\left(1+R+R^{2}\right)^{(n-1) / 2}}{(2+R)^{n}} .
$$

The principal strain-rates for an ice shelf are then:

$$
\begin{aligned}
& \dot{\varepsilon}_{1}=R^{\prime}\left(\sigma_{1}-\sigma_{3}\right)^{n} / A^{n}, \\
& \dot{\varepsilon}_{2}=R \dot{\varepsilon}_{1}, \\
& \dot{\varepsilon}_{3}=-\left(\dot{\varepsilon}_{1}+\dot{\varepsilon}_{2}\right)=-(1+R) \dot{\varepsilon}_{1},
\end{aligned}
$$

where Equation ( $8 c$ ) expresses the first invariant of strain-rate for conservation of volume $\left(\dot{\varepsilon}_{k k}=0\right)$.

Since hydrostatic pressure increases linearly with depth for an ice shelf having thickness $h_{I}$ and a constant density $\rho I$ :

$$
\sigma_{3}=\sigma_{z}=-\rho_{I} g\left(h_{I}-z\right) \text {, }
$$

where $g$ is gravity acceleration and $z=0$ at the base of the ice shelf. Substituting Equation (9) into Equation $(8 a)$ and solving for $\sigma_{1}$, gives:

$$
\sigma_{1}=A\left(\dot{\varepsilon}_{1} / R^{\prime}\right)^{1 / n}-\rho_{I} g\left(h_{I}-z\right) \text {. }
$$

The base of the ice shelf is below sea-level at depth $h_{w}$ in water of density $p_{w}$. Balancing hydrostatic pressure in a given ice column by the hydrostatic pressure of water in the column if the ice melted:

$$
\int_{0}^{h} 1 \quad \sigma_{1} d z=\int_{0}^{h}{ }^{h} \rho_{w} g\left(h_{w}-z\right) d z
$$

Substituting Equation (10) for $\sigma_{1}$, integrating, and solving for $\dot{\varepsilon}_{1}$ gives:

$$
\begin{aligned}
\dot{\varepsilon}_{1} & =\frac{R^{\prime}\left(\frac{1}{2} \rho_{I} g h_{I}^{2}-\frac{3}{2} \rho_{W} g h_{w}^{2}\right)^{n}}{\left[\int_{0}^{h_{I}} A d z\right]^{n}} \\
& =\frac{\left(1+R+R^{2}\right)^{(n-1) / 2}}{(2+R)^{n}}\left[\frac{\rho_{I} g h_{I}}{2 \bar{A}}\left(1-\frac{\rho_{I}}{\rho_{W}}\right)\right]^{n},
\end{aligned}
$$

where Equation (7) is substituted for $R^{\prime}$, buoyancy requires that $h_{W}=\left(\rho_{I} / \rho_{W}\right) h_{I}$, and the average value

$$
\bar{A}=\frac{1}{h_{I}} \int_{0}^{h_{1}} A d z \text {. }
$$

Principal strain-rates $\dot{\varepsilon}_{\text {are obtained from }}$ strain-rates $\dot{\varepsilon}_{i j}$ using the Mónr circle construction:

$$
\begin{aligned}
& \dot{\varepsilon}_{1}=\frac{1}{2}\left(\dot{\varepsilon}_{x x}+\dot{\varepsilon}_{y y}\right)+\left[\frac{1}{4}\left(\dot{\varepsilon}_{x x}-\dot{\varepsilon}_{y y}\right)^{2}+\dot{\varepsilon}_{x y}^{2}\right]^{\frac{1}{2}}, \\
& \dot{\varepsilon}_{2}=\frac{1}{2}\left(\dot{\varepsilon}_{x x}+\dot{\varepsilon}_{y y}\right)-\left[\frac{1}{4}\left(\dot{\varepsilon}_{x x}-\dot{\varepsilon}_{y y}\right)^{2}+\dot{\varepsilon}_{x y}^{2}\right]^{\frac{1}{2}}, \\
& \tan 2 \phi=2 \dot{\varepsilon}_{x y} /\left(\dot{\varepsilon}_{x x}-\dot{\varepsilon}_{y y}\right),
\end{aligned}
$$

where $\phi$ is the angle between coordinates $x, y$ and 1,2 .

Most Antarctic ice shelves occupy embayments, so that ice entering the ice shelf crosses a groundingline perimeter that exceeds the calving perimeter crossed by ice leaving the ice shelf as icebergs. Consequently, a typical flowband experiences bending converging flow from the grounding line to the calving front. Figure 1 shows bending converging flow on the Ross Ice Shelf for a flowband from the Siple Coast. The centerline of the flowband is at radius $r$ from its rotation axis $r$. The sides of the flowband are arcs about rotation axes $r^{\prime}$ and $r^{\prime \prime}$, which are displaced because flow converges. In the absence of rigid body rotation, the flowband experiences a backshear $-\Delta s$ across its width $\Delta r$ as it rotates through angle $\theta$. For local velocities $u, v$ along local rectilinear axes $x, y$, the simple shear strain $\gamma_{x y}$ and strain-rate $\dot{\gamma}_{x y}$ in the plane of the ice shelf are:

$$
\begin{aligned}
\gamma_{x y}= & \Delta s / \Delta r=\theta \Delta r / \Delta r=\theta, \\
\dot{\gamma}_{x y}= & \dot{\varepsilon}_{x y}+\dot{\omega}_{x y}=1 / 2(\partial u / \partial y+\partial v / \partial x)+ \\
& 1 / 2(\partial u / \partial y-\partial v / \partial x)=d u / d y,
\end{aligned}
$$

where $\dot{\varepsilon}_{x y}$ is the pure shear strain-rate, $\dot{\omega}_{x y}$ is the rotation rate, $d v / d x=0$, and $\dot{\varepsilon}_{x y}=\dot{\omega}_{x y}=(1 / 2) \dot{r}_{x y}=(1 / 2) \dot{\beta}$. If

axes $x, y$ conform to flow referred to cylindrical axes $\theta, r$, where the flowband width decreases from $y^{\prime}$ to $y^{\prime \prime}$ and mean flowband velocity increases from $u^{\prime}$ to $u^{\prime \prime}$ in arc length $x^{\prime}-x^{\prime \prime}$ taken along the flowband centerline, the strain-rate components are:

$$
\begin{aligned}
\dot{\varepsilon}_{x x}=\dot{\varepsilon}_{\theta \theta} & =\frac{1}{r}\left(\frac{\partial u}{\partial \theta}+v\right) \simeq \frac{\partial u}{\partial x}=\frac{u^{\prime \prime}-u^{\prime}}{x^{\prime \prime}-x^{\prime}} \\
\dot{\varepsilon}_{y y}=\dot{\varepsilon}_{r r} & =\frac{\partial v}{\partial r}=\frac{1}{2}\left(\frac{u^{\prime \prime}+u^{\prime}}{x^{\prime \prime}-x^{\prime}}\right) \ln \frac{y^{\prime \prime}}{y^{\prime}} \\
\dot{\varepsilon}_{x y}=\dot{\varepsilon}_{\theta r} & =\frac{1}{2}\left(\frac{\partial u}{\partial r}-\frac{u}{r}+\frac{1}{r} \frac{\partial v}{\partial \theta}\right) \simeq \frac{1}{2}\left(\frac{\partial u}{\partial y}-\frac{u}{r}\right)=\frac{1}{2}\left(\dot{\theta}-\frac{u}{r}\right) \\
& \simeq \frac{1}{2}\left[\frac{1}{2}\left(\frac{u^{\prime \prime}+u^{\prime}}{x^{\prime \prime}-x^{\prime}}\right) \theta-\frac{1}{2}\left(\frac{u^{\prime \prime}+u^{\prime}}{r}\right)\right]
\end{aligned}
$$

Certain implicit assumptions must now be examined. First, Equation (11) strictly applies when hydrostatic forces dominate all other forces. Thomas $(1973[\mathrm{~b}])$ treats this point in detail and my Equation 
(23) shows what other forces may be involved. Second, Thomas (1973[a]) showed that $\tau$ in Equation (1) is approximately doubled when $\rho_{I}$ is constant in Equation (12) instead of varying with depth in a realistic manner. I have assumed that this effect can be absorbed, into $A$ instead of $\tau$, so that $A$ is increased to $2(n-1) / h_{A}$ and $\dot{\varepsilon}_{1}$ computed from Equation (12) can be compared with observed values. Third, $\dot{\varepsilon}_{x x}, \dot{\varepsilon}_{y y}$, and $\dot{\varepsilon}_{x y}$, given Equations $(16)$, are the dominant surface strain-rate components for bending converging flow in a flowband containing no ice rises and free from lateral shear alongside grounding lines.

Equation (12) would be invalid unless these boundary conditions were satisfied.

The derivation of Equation (12) uses the approach presented by Hughes (1972), but it can also be obtained from the equations derived by Thomas $(1973[b])$. Stuiver and others (1981) used the Hughes (1972) approach, taking $R=\dot{\varepsilon}_{1} / \dot{\varepsilon}_{2}$ instead of $R=\dot{\varepsilon}_{2} / \dot{\varepsilon}_{1}$, where $\dot{\varepsilon}_{1}$ is the largest principal extending strain-rate in both treatments. Stuiver and others (1981) used a version of Equation (12) to examine the stability of the Ross Ice Shelf toward the Siple Coast, using data from the Ross I ce Shelf Survey (RISS) published by Dorrer and others (1969). Their conclusions will now be checked using the much better data set of the Ross I ce Shelf Geophysical and Glaciological Survey (RIGGS) published by Thomas (1976[a]) and Bentley and Jezek (in press), and the cylindrical coordinates used in Equation (16).

Figure 1 shows measured surface velocities on the Ross Ice Shelf in relation to a flowband bounded by ice streams B and D from West Antarctica. Bending converging flow is evident; the flowband has a uniformly low velocity acros the Siple Coast grounding line and has no grounding lines along its sides. For flowband transects $\mathrm{KL}, M N$, and $O P$, the approximate flowband widths are 160,200 , and $310 \mathrm{~km}$, and the approximately uniform velocities are 850,450 , and $<50 \mathrm{~m} \mathrm{a}^{-1}$, respectively. Provided that the assump-

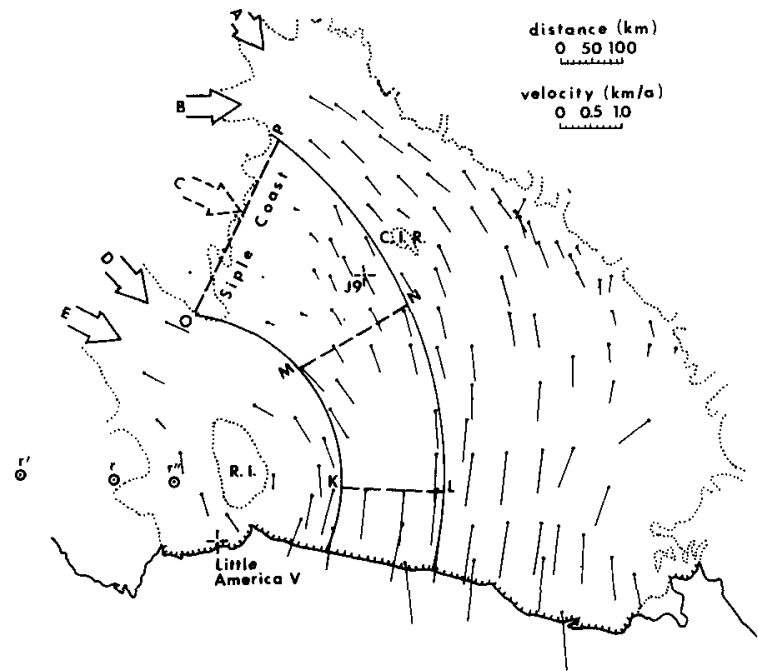

Fig.1. Flow of the Ross Ice Shelf. Identified are the calving front (hachured line), grounding lines (dotted lines), other shore-lines (solid lines), Crary Ice Rise (C.I.R), Roosevelt I sland (R.I.), core holes at $\mathrm{J} g$ and Little America V (crosses), RIGGS stations (dots), RIGGS ice velocities (vectors attached to dots), a Siple Coast flowband (between arcs centered on $r^{\prime}$ and $\left.r^{\prime \prime}\right)$, flowband transects $K L$, $M N$, and $O P$ (radiating from $r$ ), and West Antarctic ice streams $A, B, C$, and $D$ (arrows). Bending flow causes back-shear that prevents ice velocity from increasing along the bending radius. The RIGGS ice velocity map was kindly provided by C.R. Bentley, and appears in Bentley and Jezek (in press). See al so Thomas (1976[a]). tions examined in the previous discussion are valid, Table I lists data used in solving Equations (16), the strain-rate components obtained from Equations (16) and (14), and the mean ice-hardness coefficient obtained from Equation (12) for the principal surface strain-rates and average ice thicknesses $h_{I}$ in areas KLNM and MNPO obtained from data by Bentley and others (1979).

TABLE I. STRAIN-RATES AND APPARENT ICE HARDNESS FOR THE FLOWBAND IN FIGURE 1.
$M N+K L$

$x^{\prime \prime}-x^{\prime} \quad 256 \mathrm{~km}$

$u^{\prime \prime}-u^{\prime} \quad 0.4 \mathrm{~km} \mathrm{a}^{-1}$

$u^{\prime \prime}+u^{\prime} \quad 1.3 \mathrm{~km} \mathrm{a}^{-1}$

$y^{\prime \prime} / y^{\prime} \quad 0.800$

$\theta \quad-0.576 \mathrm{rad}$

$\overline{\mathrm{h}}_{\mathrm{I}}$

$\dot{\varepsilon}_{x x}$

$\dot{\varepsilon}_{y y}$

$\dot{\varepsilon}_{x y}$

$\dot{\varepsilon}_{1}$

$\dot{\varepsilon}_{2}$

$\dot{\varepsilon}_{3}$

R

$\bar{A}$
$380 \mathrm{~m}$

$$
\begin{aligned}
& 1.56 \times 10^{-3} \mathrm{a}^{-1} \\
& -0.56 \times 10^{-3} \mathrm{a}^{-1} \\
& -1.46 \times 10^{-3} \mathrm{a}^{-1} \\
& 2.30 \times 10^{-3} \mathrm{a}^{-1} \\
& -1.30 \times 10^{-3} \mathrm{a}^{-1} \\
& -1.00 \times 10^{-3} \mathrm{a}^{-1} \\
& -0.565
\end{aligned}
$$$$
8.03 \mathrm{bar} \mathrm{a}^{3 / 3}
$$

$$
\underline{O P}+M N
$$

$256 \mathrm{~km}$

$0.4 \mathrm{~km} \mathrm{a}^{-1}$

$0.5 \mathrm{~km} \mathrm{a}^{-1}$

$-0.576 \mathrm{rad}$

$500 \mathrm{~m}$

$1.56 \times 10^{-3} \mathrm{a}^{-1}$

$-0.42 \times 10^{-3} a^{-1}$

$-0.56 \times 10^{-3} \mathrm{a}^{-1}$

$1.71 \times 10^{-3} \mathrm{a}^{-1}$

$-0.57 \times 10^{-3} a^{-1}$

$-1.14 \times 10^{-3} \mathrm{a}^{-1}$

$-0.333$

10.12 bar $a^{1 / 3}$
The higher ice-hardness coefficient averaged over area MNPO compared to area KLNM can be explained in two ways. In the first explanation, ice in area MNPO is harder because it is colder, being closer in time and space to its primary source area on the West Antarctic polar plateau. Taking $\bar{A}=\bar{A}_{0} \exp (Q / n R T)$, where $Q=67 \mathrm{~kJ} \mathrm{~mol}^{-1}$ is the activation energy for creep, $n=3, R$ is the ideal gas constant, $T$ is absolute temperature, and $\bar{A}_{0}$ is a constant, average values $\bar{I}_{1}$ and $\bar{A}_{1}$ in area MNPO are related to average values $\bar{T}_{2}$ and $\bar{A}_{2}$ in area KLNM as follows:

$$
\ln \frac{\bar{A}_{1}}{\bar{A}_{2}}=\frac{Q}{n R}\left(\frac{1}{\bar{T}_{1}}-\frac{1}{\bar{T}_{2}}\right) .
$$

Using the values of $\bar{A}$ in Table $I$ and $T_{1} \simeq 257 \mathrm{~K}$ at the 39 core hole ( $C$ lough and Hansen 1979), Equation (17) gives $\bar{T}_{2} \approx 263 \mathrm{~K}$. The different $\bar{A}$ values would then reflect a temperature difference of $6 \mathrm{~K}$ between ice in areas MNPO and KLNM. However, the average temperature at the Little America $V$ core hole is $258 \mathrm{~K}$, which is only 1 deg warmer than the average ice ternperature at the 39 core hole. Given the positions of these two core holes in relation to areas MNPO and KLNM, as seen in Figure 1 , it seems unlikely that the different $\bar{A}$ values can be explained by invoking harder ice toward the Siple Coast grounding line resulting from colder ice.

In the second explanation, ice in area MNPO only appears to be harder than ice in area KLNM because $\bar{A}$ was computed from an assumption that is valid in area KLNM but not in area MNPO. This assumption is that 
the general regime of bending converging flow is not disrupted by grounding points that create small ice rises and ice rumples in area MNPO. Thomas (1976[b]) and Thomas and Bentley (1978) report evidence for numerous small grounding points toward the Siple Coast, landward of transect MN. No evidence for grounding points has been reported seaward of transect MN for the flowband in Figure 1. If grounding points exist in area MNPO, the back-stress term involving compressive stress $\tau_{c}$ in Equation (23) would keep $\dot{\varepsilon}_{z 2}$ from attaining the high value it would otherwise have if grounding points were absent. Since $\dot{\varepsilon}_{2 z}=\dot{\varepsilon}_{3}=-(1+R) \dot{\varepsilon}_{\varepsilon}$ by Equation $(8 \mathrm{c})$, the value of $\bar{A}$ computed from Equation (12) using the measured values of $\dot{\varepsilon}_{1}$ and $R$ given in Table I will appear to be larger than it actually is. Since ice at the $J 9$ and Little America $V$ core holes have quite comparable temperature profiles, we can assume that the actual $\bar{A}$ value for area MNPO is close to the $\bar{A}$ value computed for area KLNM. Combining the $\bar{A}$ value computed in area KLNM with the values of $R$ computed for areas KLNM and MNPO allows Equation (12) to give an estimate of $\dot{\varepsilon}_{1}$ if no grounding points exist in area MNPO. With no grounding points, Equation $(8 \mathrm{C})$ then gives $\dot{\varepsilon}_{z z}=-2.33 \times 10^{-3} \mathrm{a}^{-1}$ for $\mathrm{R}=-0.719$ and $\dot{\varepsilon}_{z Z}=-2.38 \times 10^{-3} \mathrm{a}^{-1}$ for $\mathrm{R}=-0.454$. Taking $\bar{h}_{I} \approx 2=500 \mathrm{~m}$ as the mean ice thickness in area MNPO (Bentley and others 1979), the ice-thinning rate due to creep is $u_{z}=\bar{h}_{1} \dot{\varepsilon}_{z_{3}} \simeq-1.18 \mathrm{~m} \mathrm{a}^{-1}$.

The above creep-thinning rate compares to a thinning rate of $-1.37 \mathrm{~m} \mathrm{a}^{-1}$ that Stuiver and others (1981) computed near the Siple Coast using RISS data (Dorrer and others 1969) for a West Antarctic flowband between ice stream $A$ and Roosevelt I sland. Stuiver and others (1981) concluded that creep thinning by this amount would exceed the combined effects of surface snow-fal1, basal freezing, and isostatic rebound that would act to create new grounding points. Consequently, in absence of an appreciable thickness gradient it appears that the Ross Ice Shelf may be becoming unpinned toward the Siple coast, rather than repinned as Thomas (1976[b]) and Thomas and Bentley (1978) concluded from their analyses of RIGGS data. The present study, also using RIGGS data, tends to confirm the conciusion of Stuiver and others (1981). Repinning presupposes an unpinned past when the above high creep thinning rates would make repinning unlikely.

Sea-water beneath the Ross Ice Shelf wedges out at a rate of about $50 \mathrm{~m}$ per $100 \mathrm{~km}$ toward the Siple Coast (Greischar and Bentley 1980). So a creep thinning rate of $-1.2 \mathrm{~m} \mathrm{a}^{-1}$ in absence of thickness advection would cause the siple coast grounding line to retreat at a rate of $1.4 \mathrm{~km} \mathrm{a}^{-1}$ after unpinning was complete, provided that surface accumulation, basal freezing, and isostatic rebound rates are all much less than the creep thinning rate. As seen in Figure 1 , velocity across the Siple Coast was too low to measure, so thickness advection is probably unimportant. Recent surface-accumulation rates near the Siple Coast are less than $80 \mathrm{~mm} \mathrm{a}^{-1}$ (C) ausen and others 1979), basal freezing between the Siple Coast and the $\mathrm{J9}$ core-hole site has averaged only $10 \mathrm{~mm} \mathrm{a}^{-1}$ over the past $600 \mathrm{a}$ (Zotikov and others 1979), and the present rate of isostatic uplift has been computed to be about $25 \mathrm{~mm} \mathrm{a}^{-1}$ near the Siple Coast (Greischar and Bentley 1980). These rates total less than $10 \%$ of the unpinned rate of creep thinning.

\section{THINNING BY MELTING}

Retreat of the Ross Ice Shelf grounding lines, both around ice rises and up ice streams, occurs when sea-level rises or when ice thins. Retreat since the last ice-age maximum was mostly a result of rising sea-level, but future retreat, if it occurs, would presumably be a consequence of climatic warming that thinned the ice shelf by melting. The surface of the ice shelf coincides with the flotation line of ice, which lies below the surface where the ice shelf is grounded. This grounded ice will float when its surface lowers to coincide with its flotation line, a condition that is met when hydrostatic pressure at the base of the ice column equals the hydrostatic pressure of water at that depth below sea-level. Analytically:

$$
\rho_{1} g\left(h_{I}+\Delta h_{I}-u_{Z} \Delta t\right)=\rho_{W} g\left(h_{W}+\Delta h_{W}+v_{Z} \Delta t\right),
$$

where $h_{I}$ is ice thickness at the grounding line, $\Delta h_{I}$ is the thickness change at grounded distance $\Delta x$ from the grounding line, $h_{W}$ is water depth at the grounding line, $\Delta h_{W}$ is the change in depth at $\Delta x, u_{z}$ is the ice-thinning rate, $v_{z}$ is the rate of rising sealevel, and $\Delta t$ is the time needed for the grounding line to retreat distance $\Delta x$. If $v_{x}$ is the groundingline retreat rate:

$$
\begin{aligned}
& \Delta h_{I}=(\alpha-\beta) \Delta x=(\alpha-\beta) v_{X} \Delta t, \\
& \Delta h_{W}=-\beta \Delta x=-\beta v_{X} \Delta t,
\end{aligned}
$$

where $\alpha$ is the surface slope and $\beta$ is the bed slope in distance $\Delta x$, both slopes positive upward. Substituting Equations (19) into Equation (18) and substituting $h_{W}=\left(\rho_{I} / \rho_{W}\right) h_{I}$, obtained when $\Delta t=0$, gives the ice-thinning rate:

$$
u_{Z}=\left[\alpha-\beta\left(1-\rho_{W} / \rho_{I}\right)\right] v_{X}+\left(\rho_{W} / \rho_{I}\right) v_{Z} \cdot
$$

Another expression for the ice-thinning rate is:

$$
u_{z}=\dot{a}+h_{I} \dot{\varepsilon}_{z z}-(\alpha-\beta) u_{x},
$$

where is the net surface and basal melting rate, $\dot{\varepsilon}_{z z}$ is the creep-thinning rate of ice, and $u_{x}$ is the average ice velocity across the grounding line, all measured at the grounding line. Equating Equations (20) and (21) and solving for the groundingline retreat rate gives:

$$
v_{x}=\frac{\left(\rho_{W} / \rho_{I}\right) v_{z}-(\alpha-\beta) u_{x}+h_{I} \dot{\varepsilon}_{Z Z}+\dot{a}}{\alpha-\beta\left(1-\rho_{W} / \rho_{I}\right)} .
$$

Except for the $v_{7}$ term, Equation (22) was derived by Thomas (1977). Observationally, ux can be very large for ice streams but is almost nil for ice rises, $\alpha$ is much smaller for ice streams than for ice rises, and $\beta$ is generally negative for ice streams and is always positive for ice rises.

Consider a flowband that has width when it crosses the ice-shelf grounding line, has a length $s$ from the grounding line to the calving front, and encounters an ice rise of radius $r$ on the ice shelf. The creep-thinning rate at the grounding line is then:

$$
\dot{\varepsilon}_{Z Z}=\left[\frac{(1+R) R^{\prime}}{\bar{A}^{n}}\right]\left[\frac{1}{2} \rho_{I} g h_{I}\left(1-\frac{\rho_{I}}{\rho_{W}}\right)-2\left(\frac{s}{W}\right) \tau_{s}-2\left(\frac{r}{W}\right) \sigma_{C}\right]^{n},
$$

where $\dot{\varepsilon}_{z z}=\dot{\varepsilon}_{3}$ is related to $\dot{\varepsilon}_{1}$ by Equation $(8 \mathrm{c}), \mathrm{R}^{\prime}$ expresses the degree of convergence or divergence of the flowband according to Equation (7), the first term is the longitudinal tensile stress along the flowband derived from Equation (12) for pure shear, the second term is the lateral shear stress alongside the flowband that exists if the average flowband velocity exceeds the average ice-shelf velocity on either side, and the third term is the longitudinal compressive stress between the ice rise and the grounding line. All terms act at the grounding line. Thomas (1973[a]) has $\sigma_{c}$ decreasing inversely with distance up-stream from ice rises. 
Comparing Equations (22) and (23) highlights various interactions between changing boundary conditions for ice shelves. Most flowbands on an ice shelf begin as ice streams. If an ice stream punches through the ice shelf, $\tau_{s}+0$ and the grounding line may retreat rapidly up the ice stream. If the grounding line retreats faster than the calving front, $s$ could increase and thereby slow retreat of the grounding line. If the flowband thins during this time, the resulting reduction of $r$ could accelerate retreat of the grounding line. If the calving front retreats past the ice rise, $\sigma_{c}=0$ and retreat of the grounding line may be accelerated even more.

The most important applications of Equations (22) and (23) are for retreat of ice-shelf grounding lines across ice streams and around ice rises. For ice streams we expect that $u_{x} \gg 0$ during a surge, $\dot{\varepsilon}_{z z}>0$ under all conditions, $\dot{a}<0$ if katabatic winds and tidal pumping ablate surface and basal ice, and $\beta<0$ unless a bedrock sill exists. For ice rises we expect that $u_{x} \simeq 0$ at all times, $\dot{\varepsilon}_{z z}<0$ on the up-stream side and $\dot{\varepsilon}_{z Z}>0$ on the down-stream side and tend to be offset by basal melting and freezing, $\alpha>0$ from surface snow-fall and a $<0$ from basal tidal pumping, and $\beta>0$ at all times.

Tidal pumping might ablate basal ice along the grounding line in two ways. Basal ice could be eroded by a slurry of sand entrained during tidal flushing, and also might be melted by frictional heat generated in water flushed back and forth in the tidal zone. Tidal pumping converts gravitational potential energy $E_{p}$ into a fraction $f$ of kinetic energy $E_{K}$ and a fraction ( 1 - f) of thermal energy $E_{T}$, which are released in the tidal zone. In broad terms, Ep released during a tidal cycle is the tidal gravity force exerted over the mean elevation change $\delta z$ that allows length $\delta y$ of grounding line to sweep across distance $\delta \mathrm{x}$ :

$E_{p}=f E_{p}+(1-f) E_{p}=E_{K}+E_{T}=\left(p_{I} g \delta z\right)(\delta x \delta y) \delta z$

where the tidal gravity force is the tidal hydrostatic pressure change $\rho I g \delta z$ acting over area $\delta x \delta y$ swept by the grounding line during one tidal cycle. The average velocity of water flushed in and out of the tidal zone during the rise and fall of tide is:

$$
\begin{aligned}
u_{W} & =\left(2 E_{K} / m_{W}\right)^{1 / 2}=\left[2 f E_{p} / \rho_{W} \delta x \delta y \delta z\right]^{1 / 2} \\
& =\left(4 f\left(\rho_{I} / \rho_{W}\right) g \delta z\right]^{1 / 2},
\end{aligned}
$$

where $m_{W}$ is the mass of water moved back and forth in the tidal zone. The rate of basal melting in the tidal zone is:

$$
\begin{aligned}
\dot{a} & =365 E_{T} / Q_{L} \rho_{W} \delta x \delta y=365(1-f) E_{P} / Q_{L} \rho_{W} \delta x \delta y \\
& =365(1-f)\left(\rho_{I} / \rho_{W}\right) g \delta z^{2} / Q_{L}
\end{aligned}
$$

where 365 tidal cycles occur per year (one cycle per day). Basal water wedges out at about $50 \mathrm{~m}$ per $100 \mathrm{~km}$ toward the siple Coast grounding line of the Ross Ice Shelf (Greischar and Bentley 1980), where Williams and Robinson (1979) measured $\delta z \simeq 2 \mathrm{~m}$, so $2 \delta \mathrm{z} / \delta \mathrm{x}=5 \times 10^{-4}$ gives $\delta \mathrm{x} \simeq 8 \mathrm{~km}$. Assuming that $f=0.5$, Equation (25) gives $u_{W}=6 \mathrm{~m} \mathrm{~s}^{-1}$ and Equation (26) gives $a=20 \mathrm{~mm} a^{-1}$. Sand could be entrained for these $u_{W}$ values (Cacchione and Southard 1974), and could then erode basal ice in the tidal zone; how much erosion is unclear.

Widespread surface melting may affect the local melting rates of basal ice. Robin (1979) noted that ocean currents at the freezing point lose heat as they descend under ice shelves and sweep along iceshelf grounding 1 ines. This heat loss melts basal ice because the pressure-melting point decreases with increasing hydrostatic pressure. Similarly, surface melt water on an ice shelf must lose heat as it descends into crevasses, and the lost heat melts crevasse walls once they become temperate. The descending surface melt water could displace the more dense sea-water that fills crevasses to sea-level when surface crevasses join bottom crevasses. It is proposed that heat lost during descent into crevasses could melt basal ice when the crevasses fracture the entire ice thickness. If volume $V_{W}$ of water at the surface melts volume $V_{I}$ of ice at the base, the volune ratio is:

$$
\frac{V_{I}}{V_{W}}=\frac{C_{P}}{Q_{L}} \delta T_{M}=\frac{C_{P}}{Q_{L}}\left(\frac{\partial T_{M}}{\delta P}\right) P=\frac{C_{P}}{Q_{L}}\left(\frac{\partial T_{M}}{\delta P}\right) \rho_{I} g h_{I},
$$

where $C_{p}=4.18 \times 10^{3} \mathrm{~J} \mathrm{~kg}^{-1} \mathrm{~K}^{-1}$ is the specific heat of water, $Q_{L}=334.4 \times 10^{3} \mathrm{~J} \mathrm{~kg}^{-1}$ is the latent heat of water, and $\left(\partial T_{M} / \partial P\right) \simeq-8.9 \times 10^{-3}{ }^{\circ} \mathrm{C}$ bar $^{-1}$ is the change in the pressure-melting point $T_{M}$ of ice with hydrostatic pressure $P=\rho_{I} g h_{I}$. If melt water from a surface ablation rate of $0.1 \mathrm{~m} \mathrm{a}^{-1}$ on the $5.2 \times 10^{5} \mathrm{~km}^{2}$ area of the Ross Ice Shelf reaches the base through grounding-1ine crevasses that fracture ice averaging $500 \mathrm{~m}$ thick, Equation (27) predicts that $0.26 \mathrm{~km}^{3} \mathrm{a}^{-1}$ of basal ice would be melted. If basal melting were confined to a band $100 \mathrm{~m}$ wide along the crevasses, a basal melting rate of about $0.8 \mathrm{~m} \mathrm{a}^{-1}$ would occur, should this mechanism operate, along the $2400 \mathrm{~km}$ of Ross Ice Shelf grounding lines. This eightfold increase when the surface melting rate is transformed into a basal melting rate along grounding 1 ines could be the major effect of $\mathrm{CO}_{2}$-induced climatic warming on ice shelves.

\section{CONCLUSIONS}

Creep-thinning rates for ice shelves lying in confined embayments are reduced if the general regime of bending converging flow is disrupted by ice rises. An analysis of RIGGS data leads to the conclusion that the Ross I ce Shelf is becoming unpinned instead of repinned toward the Siple Coast. Unpinning should facilitate grounding-line retreat. I ce-melting rates along grounding lines were examined for tidal pumping and descent of surface melt water into crevasses. At the present time, only tidal pumping would facilitate unpinning and grounding-line retreat. However, should future climate warming place the Ross Ice Sheif in an ablation zone, surface melt water entering tidal flexure crevasses could become the dominant process facilitating unpinning and grounding-line retreat. Basal melting by warm ocean currents has been discussed by Robin (1979), and was not examined.

\section{ACKNOWLEDGEMENT}

This work was supported by grant DPP-8006503 of the US National Science Foundation.

\section{REFERENCES}

Barrett $P$ J 1975 Seawater near the head of the Ross Ice Shelf. Nature 256(5516): 390-392

Bentley $C R$, Jezek $K C$ In press. RISS, RISP, and RIGGS: post-IGY glaciological investigations of the Ross Ice Shelf in the U.S. program. Journal of the Royaz Society of New Zealand

Bentley C R, Clough J W, Jezek K C, Shabtaie S 1979 Ice-thickness patterns and the dynamics of the Ross Ice Shelf, Antarctica. Joumal of Glaciology 24(90): 287-294

Cacchione D A, Southard J B 1974 Incipient sediment movement by shoaling internal gravity waves. Journal of Geophysical Research 79(15): 2237-2242

Clausen H B, Dansgaard W, Nielsen J O, CTough J W 1979 Surface accumulation on Ross Ice Shelf. Antarctic Journal of the United States 14(5): 68-72

Clough J W, Hansen B L 1979 The Ross Ice Shelf Project. Science 203(4379): 433-434 
Dorrer E, Hofmann W, Seufert W 1969 Geodetic results of the Ross Ice Shelf Survey expeditions, 1962-63 and 1965-66. Joumat of Glaciology 8(52): $67-90$

Fastook J L, Schmidt WF 1982 Finite element analysis of calving from ice fronts. Annats of Glaciology 3: 103-106

Glen J W 1958 The flow law of ice. Intemationat Ascocialion of Seientific Hydrology Publication 47 (Symposium of Chamonix - physics of the Motion of Ice): 171-183

Greischar L L, Bentley C R 1980 Isostatic equilibrium grounding Tine between the West Antarctic inland ice sheet and the Ross ice Shelf. Nature 283(5748): 651-654

Hughes T J 1972 Is the West Antarctic ice sheet disintegrating? Scientific justification. ISCAP Bulletin (Ohio State University) 1

Hughes T J 1979 Byrd Glacier. Antaretic Journal of the United states 14(5): 88-91

Robin $G$ de Q 1979 Formation, flow, and disintegration of ice shelves. Joumal of Glaciozogy 24(90): 259-271

Stuiver $M$, Denton $G H$, Hughes T J, Fastook J L 1981 History of the marine ice sheet in West Antarctica during the last glaciation: a working hypothesis. In Denton $\mathrm{G} H$, Hughes $\mathrm{T} J$ (eds) The Zast great ice sheets. New York etc, Wiley-Interscience: $319-436$

Thomas RH 1973[a] The creep of ice shelves: interpretation of observed behaviour. Joumal of Gzacioloris 12(64): 55-70

Thomas R H 1973[b] The creep of ice shelves: theory. Joumal of Glaciology 12(64): 45-53

Thomas R H 1976[a] Ice velocities on the Ross Ice Shelf. Antarctic Joumat of the United States $11(4): 279-281$

Thomas R H 1976[b] Thickening of the Ross Ice Shelf and equilibrium state of the West Antarctic ice sheet. Nature 259(5540): 180-183

Thomas RH 1977 Calving bay dynamics and ice sheet retreat up the St Lawrence valley system. Geographie Physique et Quaternaire 31(3-4): $347-$ 356

Thomas R H, Bentley C R 1978 The equilibrium state of the eastern half of the Ross Ice Shelf. Joumal of Glaciology 20(84): 509-518

Williams R T, Robinson E S 1979 0cean tide and waves beneath the Ross Ice Shelf, Antarctica. science 203(4399): 443-445

Zotikov I A, Zagorodnov V S, Raikovsky J V 1979 Sea ice on bottom of Ross Ice Shelf. Antarctic Joumat of the United States 14(5): 65-66 